\title{
The Effect of Pistacia Atlantica and Hypericum Perforatum as a Healing Accelerator Remedy on Induced Oral Mucositis in Male Golden Hamster
}

\author{
Farnaz Farrokhi ${ }^{1 *}$, Nader Tanideh ${ }^{2}$, Sepideh Fekri ${ }^{3}$, Omid Koohi-Hosseinabadi ${ }^{4}$, Azadeh Andisheh Tadbir ${ }^{5}$ \\ and Maryam Mardani ${ }^{6}$ \\ ${ }^{1}$ Student Research Committee, School of Dentistry, Shiraz University of Medical Sciences, Shiraz, Iran. \\ ${ }^{2}$ Stem Cell Technology Research Center and Pharmacology Department, Shiraz Medical School, Shiraz University of Medical Sciences, Shiraz, Iran. \\ ${ }^{3}$ Student Research Committee, School of Dentistry, International Branch, Shiraz University of Medical Sciences, Shiraz, Iran. \\ ${ }^{4}$ Laboratory Animal Center, Shiraz University of Medical Sciences, Shiraz, Iran
}

${ }^{5}$ Prevention of Oral and Dental Diseases Research Center, School of Dentistry, Shiraz University of Medical Sciences, Shiraz, Iran.

${ }^{6}$ Department of Oral and Maxillofacial Medicine, School of Dentistry, Shiraz University of Medical Sciences, Shiraz, Iran.

Submission: February 06, 2017; Published: March 07, 2017

*Corresponding author: Nader Tanideh, PhD, Stem Cell Technology Research Center and Pharmacology Department, Shiraz Medical School, Shiraz University of Medical Sciences, Shiraz, Iran, Tel: +989177160017; Email: tanidehn@gmail.com

\begin{abstract}
Oral mucositis is a painful condition that occurs as a side effect of chemotherapy. P. atlantica and H. perforatum have long been known for their anti-inflammatory and anti-oxidative properties as an alternative medicine. This study evaluated the healing effects of extraction of $P$. atlantica and $H$. perforatum, on 5-FU induced oral mucositis in golden hamsters by histopathology, clinically, and anti-oxidative assessments. Oral mucositis was induced in 60 male golden hamsters by administration of $5-\mathrm{FU}(60 \mathrm{mg} / \mathrm{kg})$, on days 0,5 , and 10 of the study. Animals were randomly divided in 5 groups, ( $\mathrm{n}=12$ ). They were treated with hydro-alcoholic extract of H. perforatum (topical gel 10\%) (Group 1), P. atlantic oil extract (topical gel 10\%) (Group 2), the combination of topical gel 10\% of P. atlantica, and topical gel 10\% of H. perforatum (Group 3), gel base group (Group 4) that were all compared with the control group (Group 5) from day 12 to day 18. On days 15 and 18 of the experiment cheek pouch were examined visually for macroscopic scoring and excisional biopsies were obtained for microscopic scoring. Tissue MDA and MPO levels were assessed. The data were statistically analyzed by analysis of variances and kruskal-wallis test. Healing of oral mucositis was significantly improved both clinically and histopathologically $(\mathrm{P}$-value $<0.05)$ in group 3 in comparison with the other four groups. It seems that treatment with H. perforatum and P. atlantica gel, specially $10 \%$ gel concentration, can facilitate the healing of oral mucositis induced by chemotherapy (5-FU).
\end{abstract}

Keywords: Hypericum perforatum; Oral mucositis; Pestatica atlantica; Hamester

Abbreviation: P. Atlantica: Pistacia Atlantica; H. Perforatum: Hypericum Perforatum; OM: Oral Mucositis; MDA: Malon Di Aldehyde; MPO: Myelo Per Oxidase; 5-FU: 5-Fluoro Uracil; NSAID: Non Steroid Anti-Inflammatory Drug

\section{Introduction}

Oral mucositis (OM), an inflammatory response to radiotherapy/chemotherapy in patient with head and neck cancer, is very painful condition. OM has a direct effect on quality of life in patients with dysphagia, pain, and it interferes with nutrition swallowing and verbal communication, gingival bleeding, infection and weight loss. However, $\mathrm{OM}$ increases the hospitalization duration and treatment cost [1-3]. Until now, the available strategy therapies such as dental care, anti-oxidant agents, antiinflammatory agents, steroids, NSAIDs, topical antiseptic, and antimicrobial agents, cryotherapy, mucosal protectors, antibiotics, pure honey and herbal medicines are palliative, but an effective therapeutic agent for OM has long remained elusive $[2,4,5]$.

The use of biological products such as palifermin is effective, but most patients cannot afford it because of its high costs. Therefore, herbal medicines are most commonly used for OM as they are cheaper with less toxicity than synthetic drugs. Herbal therapies with antifungal, antibacterial, anti-inflammatory, antioxidant, wound healing, and immune stimulatory characteristics such 
as Glycyrihiza glabra, payayor, Zizyphys jujube, calendula officincalis carum carvi, and Curcuma longa could be used in OM treatment. [2,3,6-8]. Pistacia atlantica (subsp. Mutica) trees grow in the western, eastern and central parts of Iran. The fruit of this tree has long been used as snack and also for treatment of peptic ulcer, kidney stones, dyspepsia, wound heading, hepatica inflammation, toothache, diabetes, expectorant antitumor, and mycosis. P. atlantica contains saturated fatty acids like palmitic acid, unsaturated fatty acid such as; trepenoids, plamitoleic acid, oleic acid, lineoleic acid, and unsaponifiable matter which is considered to be the highest tocopherols and tocoterinols, phenolic compound such as gallic acid as antioxidant. Trepenoids have anti-inflammatory and antinocieptive activity [9-10].

Hypericum perforatum (St. John's Wort), as a herbal medicine, can be identified with its golden yellow flowers and it is indigenous to Europe, western Asia and northern Africa. Its flowers contain red liquid which comprises of biologically active compounds. $H$. perforatum plants have been used in medicine for centuries. $H$. perforatum is commercially available in forms of tablet, capsule and tea $[11,12]$. Wound-healing effect of $H$. perforatum can be used for the treatment of burns, depression, ulcerative colitis, analgesic, antibiotic, antiviral, and diuretic. Anti-oxidant activity of $H$. perforatum is like the in vitro and in vivo activity of vitamin E that inhibits free radical and lipid peroxidation. Several active components of $H$. perforatum are hypericin, quercetin, hyperforin, flavonoids, and xanthone derivatives [12]. This study aims to evaluate the efficacy of $H$. perforatum and P. atlantica on induced $\mathrm{OM}$ in male golden hamsters.

\section{Materials and Methods}

\section{Animals}

Sixty male golden hamsters (8-10 weeks old), 105 \pm 5 g, were used after approval of the University Ethic Committee 9003. All animals had access to normal diet, water and were placed in a standard cage $60^{*} 40^{*} 18$, at $20^{\circ} \pm 2,55 \pm 5 \%$ humidity in a $12 \mathrm{~h}$ light and $12 \mathrm{~h}$ dark cycle.

\section{Chemotherapy induced oral mucositis}

The animals were randomly divided into five groups ( $n=12)$. All animals received intraperitoneal injections of 5 -fluorouracil (5-FU $/ 60 \mathrm{mg} / \mathrm{kg})$ during days 0,5 , and 10 . Three horizontal superficial scratches were made on the cheek pouch with the tip of a 19 gauge sterile needle across the everted cheek pouch once daily on days 2 and 3 in order to simulate the clinical effect of chronic irritation. The severity of oral mucositis was observed on the $12^{\text {th }}$ day. Subsequently, they were treated with topical gel $10 \%$ hydro-alcoholic extract of H. perforatum (Group 1), topical gel 10\% P. atlantica fruit oil extract (Group 2), topical gel 10\% P. atlantica fruit oil extract in combination with $10 \%$ hydro-alcoholic extract of $H$. perforatum (Group 3), in the $4^{\text {th }}$ group the subjects received the gel base, and finally the control group (Group 5) received no treatment. All groups received topical gel (wound was completely covered) except the fifth group. To ensure that topical gel was not swallowed, animals were not given any food or drink for $90 \mathrm{~min}$ after it was applied on their cheek pouches. Six hamsters were randomly selected from each group and euthanized on the $15^{\text {th }}$ and $18^{\text {th }}$ day. Both cheek pouches mucosa were harvested.

\section{Macroscopical study}

We scored lesions based on our observation. Inflammatory aspects such as erythema, hyperemia, hemorrhagic areas, epithelial ulcerations, and abscesses were evaluated in a singleblind fashion for macroscopic analysis (Table 1) [13].

Table 1: Macroscopical scoring system which is obtained from the study by Lima et al. [13].

\begin{tabular}{|c|c|}
\hline Scores & Description \\
\hline 0 & $\begin{array}{r}\text { Normal cheek pouch with erythema and hyperemia } \\
\text { absent or discreet; absence of hemorrhagic areas, } \\
\text { ulcerations or abscess }\end{array}$ \\
\hline 1 & $\begin{array}{r}\text { Moderate erythema and hyperemia; absence of } \\
\text { hemorrhagic areas, ulcerations, or abscess. }\end{array}$ \\
\hline 2 & $\begin{array}{r}\text { Severe erythema and hyperemia; presence of } \\
\text { hemorrhagic areas, small ulcerations, or scarred } \\
\text { tissue, absence of abscess }\end{array}$ \\
\hline 3 & $\begin{array}{c}\text { Severe erythema and hyperemia; presence of } \\
\text { hemorrhagic areas, extensive ulcerations, and } \\
\text { abscesses }\end{array}$ \\
\hline
\end{tabular}

\section{Histopathological study}

Tissues which were taken from the right cheek pouches were fixed in $10 \%$ formalin. Sections were stained with Haematoxylin and Eosin. The specimens were examined histopathologically and received scores of $0-3$ (Table 2) [13].

Table 2: Histopathological scoring system which was obtained from the study by Lima et al. [13].

\begin{tabular}{|c|c|}
\hline Score & Descriptions \\
\hline 0 & $\begin{array}{c}\text { Normal epithelium and connective tissue without } \\
\text { vasodilatation; absent or mild inflammatory infiltrate; } \\
\text { absence of bleeding, ulcers and abscesses }\end{array}$ \\
\hline 1 & $\begin{array}{c}\text { Mild vascular hyperaemia; areas of re-epithelialization; } \\
\text { mild inflammatory infiltrate with a prevalence of } \\
\text { mononuclear cells; no haemorrhagic areas, ulcerations } \\
\text { or abscesses }\end{array}$ \\
\hline 2 & $\begin{array}{c}\text { Moderate vascular redness; areas of epithelial } \\
\text { degeneration; inflammatory infiltration with prevalence } \\
\text { of neutrophils; haemorrhagic areas, oedema and } \\
\text { occasional ulcerations; absence of abscesses }\end{array}$ \\
\hline 3 & $\begin{array}{c}\text { Severe hyperaemia and vascular vasodilatation; } \\
\text { inflammatory infiltration with prevalence of neutrophils; } \\
\text { haemorrhagic areas, edema, extensive ulcerations, and } \\
\text { abscesses. }\end{array}$ \\
\hline
\end{tabular}

\section{Measurement of tissue malondialdehyde (MDA)}

Tissues from the left cheek pouches were sent to the laboratory in the faculty of Pharmacy in cryo-tubes for MDA to be measured. MDA is an index of lipid peroxidation. Tissues weighing between 0.15 and $0.2 \mathrm{~g}$ were cut and mixed and homogenized with phosphate buffer solution in a ratio of $1 / 5$. The homogenized tissues $(400 \mathrm{ml})$ were mixed with $800 \mathrm{ml}$ of trichlor-oacetic acid, 
and centrifuged for $30 \mathrm{~min}$ (3000 rpm). Next, $600 \mathrm{ml}$ of the samples were mixed with $150 \mathrm{ml}$ of $1 \%$ thiobarbituric acid and positioned in a water bath for $15 \mathrm{~min}$. After cooling, $6 \mathrm{ml}$ of $\mathrm{n}$-butanol was added and they were centrifuged for 10 min (3000rpm). Finally, butane phase absorption was read with spectrophotometer at a wavelength of 532nm [14]. Tetraethoxy propane was used as control. The MDA tissue concentration was calculated as follows: MDA $(\mathrm{nmol} / \mathrm{ml})=[($ absorbance of the test sample - absorbance of the negative control) + 0.0606]/0.0537 .

\section{Measurement tissue myeloperoxidase (MPO)}

Harvested cheek pouches were weighed and homogenized in a solution containing $0.5 \%(\mathrm{w} / \mathrm{v})$ hexadecyltrimethyl ammonium bromide dissolved in $10 \mathrm{mmol} / \mathrm{l}$ potassium phosphate buffer $\mathrm{pH}$ 7.4) and centrifuged for $30 \mathrm{~min}$ at $20000 \mathrm{~g}$ at $4{ }^{\circ} \mathrm{C}$. An aliquot of supernatant was then removed and added to a reaction mixture containing $1.6 \mathrm{mmol} / \mathrm{l}$ tetramethylbenzidine and $0.1 \mathrm{mmol} / \mathrm{l}$ hydrogen peroxide $\left(\mathrm{H}_{2} \mathrm{O}_{2}\right)$. MPO activity was measured in tissues by assays using hydrogen peroxide and o-dianisidinedihydrochloride Results as substrates. The absorbance rate was measured by spectrophotometer at $650 \mathrm{~nm}$. MPO activity was defined as the quantity of enzyme required to degrade $1 \mathrm{mmol}$ of $\mathrm{H}_{2} \mathrm{O}_{2}$ at $37{ }^{\circ} \mathrm{C}$. Enzyme activity was expressed in U/g wet tissue [15].

\section{Statistical analysis}

Normal distributions of data were assessed using Kolmogorov Smirnov test. The MDA and MPO levels were compared in each group on the $12^{\text {th }}, 15^{\text {th }}$ and $18^{\text {th }}$ day, using non-parametric KruskalWallis $\mathrm{H}$ tests to assess the differences between groups on MDA level and MPO activities, stereological and histopa 7 thological scores. The Mann- Whitney U-test with Bonferroni correction $(0.05: 6=0.0083)$ was used to compare qualitative factors such as histopathological and macroscopical scores between groups on $12^{\text {th }}, 15^{\text {th }}$ and $18^{\text {th }}$ day. The data are presented as the mean \pm standard deviation. SPSS software version 19 (SPSS Inc., Chicago, IL, USA) was used for statistical analysis of data. Graphpad Prism 5 (GraphPad Software Inc., La Jolla, CA, USA) was used to draw the graphs. P-value $\leq 0.05$ was considered statistically significant.

\section{Tissue MDA level assessment}

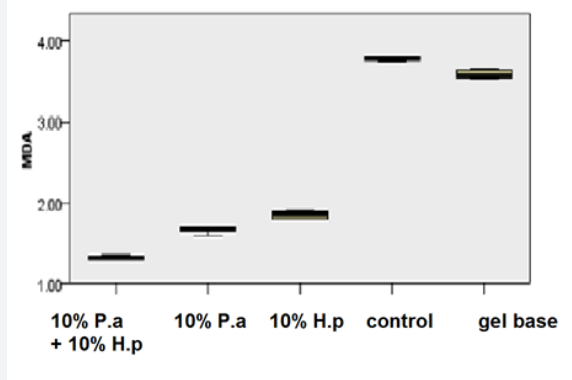

A

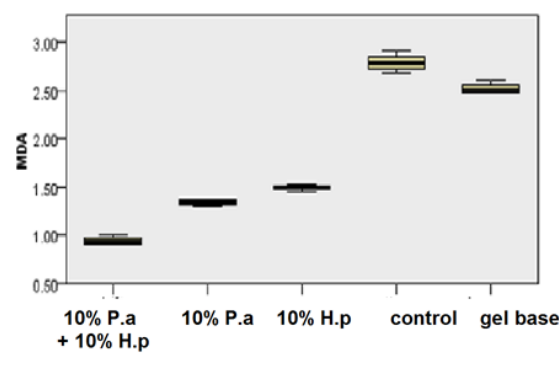

B

Figure 1: Comparison of tissue malondialdehyde (MDA) concentrations between three different groups in two days of sampling A) MDA concentration on $15^{\text {th }}$ day $B$ ) MDA concentration on $18^{\text {th }}$ day.

Tissue MDA activity in study groups on 15th and 18thdays are shown in Figure 1 . On both days $15^{\text {th }}$ and $18^{\text {th }}$, tissue MDA level evaluation scores for the mixed group was significantly lower than the gel-base group and the control group ( $\mathrm{p}<0.001)$. MDA level concentration for the mixed group was lower than $10 \%$ of

\section{Tissue MPO level assessment}

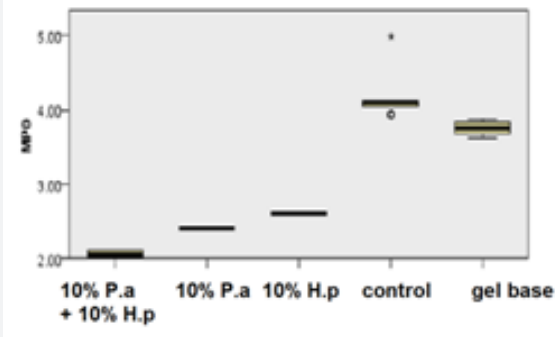

A Figure 2: Comparison of tissue myeloperoxidase (MPO) activity between three different groups in two days of sampling A) MPO activity
on $15^{\text {th }}$ day B) MPO activity on $18^{\text {th }}$ day. 
Tissue MPO activity in study groups on $15^{\text {th }}$ and $18^{\text {th }}$ day are shown in Figure 2. On both days 15 and 18, tissue MPO level evaluation scores for the mixed group was significantly lower than the gel-base group and the control group $(p<0.001)$. MPO level concentration for the mixed group was lower than the 10\% of $H$. Macroscopic assessment perforatum group ( $\mathrm{p}=0.002$ in both days). On $15^{\text {th }}$ and $18^{\text {th }}$ days, MPO level concentration for the $10 \%$ of $P$. atlantica group was lower than gel-base group $(\mathrm{p}=0.002)$, and also lower than the control group $(\mathrm{p}<0.001)$. MPO concentration for the $10 \%$ of $H$. perforatum group was lower than control group $(\mathrm{p}=0.002)$.

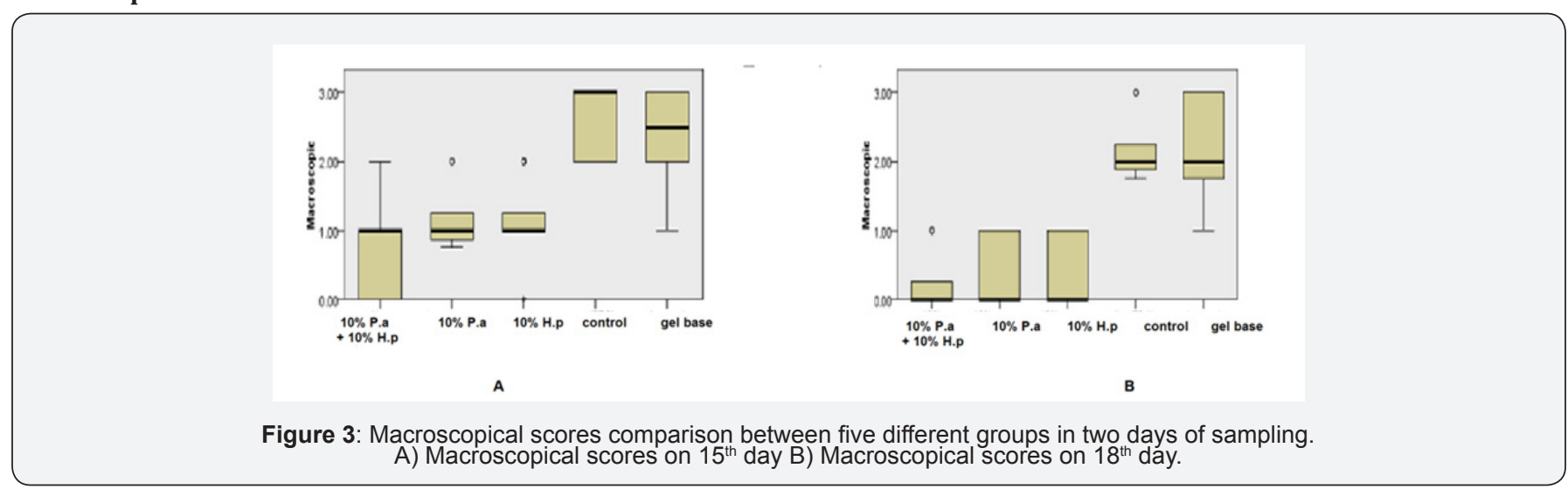

Macroscopic evaluation scores in the study groups on $15^{\text {th }}$ and $18^{\text {th }}$ days are shown in Figure 3. On both days 15 and 18, macroscopic evaluation scores for the mixed group was significantly lower than the gel-base group and the control group $(\mathrm{p}<0.001)$, which means better healing in the mixed group. Macroscopic scores of $10 \%$ P. atlantica group was lower than the control group $(\mathrm{p}<0.001$ in Microscopic assessment both days) and also lower than the gel base on days 15 and 18 ( $\mathrm{p}=0.002$ vs. $\mathrm{p}<0.001$ ). On $15^{\text {th }}$ and $18^{\text {th }}$ days, macroscopic scores of the control group was more than $10 \%$ of $H$. perforatum group $(\mathrm{p}<0.001)$. On day $15^{\text {th }}$ and $18^{\text {th }}$, macroscopic scores $10 \%$ of $H$. perforatum group was lower than the base gel group ( $\mathrm{p}=0.004 \mathrm{vs}$. $\mathrm{p}<0.001)$.

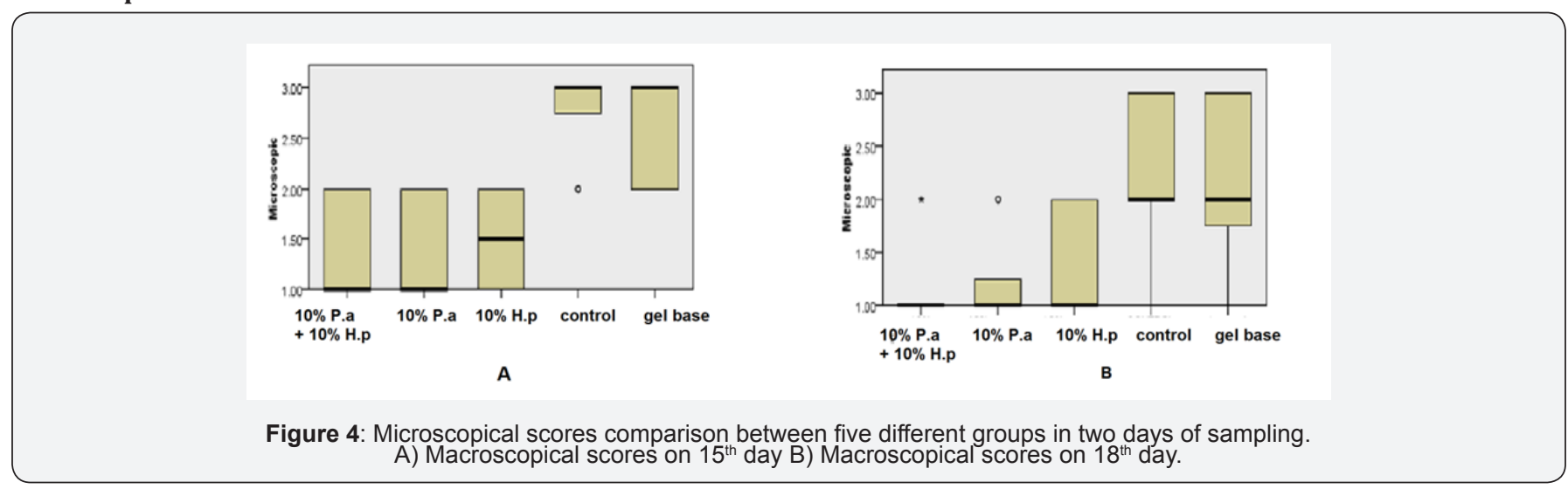

Microscopic evaluation scores in study groups on $15^{\text {th }}$ and $18^{\text {th }}$ days are shown in Figure 4. On both days 15 and 18, microscopic evaluation scores for the mixed group was significantly lower than the gel-base group and the control group $(\mathrm{p}<0.001)$. Microscopic scores of $10 \%$ P. atlantica group was lower than the control group ( $\mathrm{p}<0.001$ in both days), and also lower than gel base on days 15 and 18 ( $\mathrm{p}=0.001$ vs. $\mathrm{p}=0.004$ ). On day 15 and 18, microscopic scores $10 \%$ of $H$. perforatum group was lower than the base gel group ( $\mathrm{p}=0.002$ vs. $\mathrm{p}=0.035)$ and also lower than the control group on day 15 and 18 ( $\mathrm{p}<0.001$ vs. $\mathrm{p}=0.013)$.

\section{Discussion}

In this study, histopathological, macroscopical and anti -oxidant markers of $P$. atlantica and $H$. perforatum were evaluated in the induced oral mucositis in male golden hamsters. We showed that the mixed gel $(10 \%$ P. atlantica $+10 \%$ H. perforatum $)$ yield better results on healing process of $\mathrm{OM}$ in comparison with the other groups both on $15^{\text {th }}$ and $18^{\text {th }}$ day.

NSAIDs and steroidal drugs are usually prescribed for inflammatory diseases. Although several studies have shown the effect of combined protein and herbal plants accelerate healing and anti-inflammatory effects in $\mathrm{OM}$ in human and animal models, but not all of them showed high efficacy for OM treatment $[12,16,17]$. Tanideh et al. [12], showed that oral administration of $H$. perforatum haydro alcoholic extract was more effective than the topical gel on OM. Additionally, Samadi et al. [16], described that using H. perforatum ointment had positive effects on cesarean wound. $H$. perforatum stimulates fibroblasts to produce more collagens, so that the wound contraction accelerates [17]. Since 
normal flora of oral cavity gets the opportunity to infect the oral mucosa lesions, hence, anti-microbial agents can be beneficial [8]. H. perforatum has potential antibiotic properties [18].

Conforti et al. [19] showed that the accelerated healing effect of $H$. perforatum with its non-cytotoxic and anti-inflammatory properties is due to multiple components such as flavonoids and biapigenin. Couladis et al. [20] showed that the antioxidant activities of vitamin $E$ are as effective as those of Hypericum species such as rutin, quercetin, and chlorogenic acid. The protective role of $H$. perforatum extracts on the process of lipid peroxidation was established by measuring the formation of MDA. Božin et al. [21] showed a notable inhibitory potency of lipid peroxidation of $\mathrm{H}$. perforatum extracts. Some studies have investigated the effect of H. perforatum on periodontitis in animal model and their findings showed that myeloperoxidase levels can be reduced significantly by hypericum treatment in the gingivomucosal tissues. [22] Dost et al. [11] found that $H$. perforatum was effective in decreasing MDA levels in TNBS-induced colitis in rats due to its antioxidant properties.

In traditional Iranian medicine, different parts of Pistacia species, such as lentiscus, atlantica, khinjuk, and terebinthus, with their effective wound healing properties have been used in the treatment of brain and gastrointestinal disorders and different inflammatory diseases [23]. Tanideh et al. [24] showed the efficacy of $P$. atlantica on healing of acetic acid induced colitis in rats.

The fruits of P. atlantica are found to be rich in proteins, fibers, and unsaturated fatty acids, suggesting their value as a food source. The major components of P. atlantica are $\alpha$-tocopherols and important sterols that have antioxidant properties and health benefits such as; being precursors of vitamin $\mathrm{D}$ and lowering blood cholesterol [25].

There are several studies that have investigated the bioactive agent of $P$. atlantica. $\alpha$ - pinene, tocopherol and teriterpenic acid which are three important components of this fruit [26,27]. They have also declared that this herbal medicine can be useful for treating GI ulcers, strengthening gum [28,29]. Farnoosh et al. [28], expressed that $48 \%$ of composition of nonsoapebale P. atlantica oil consist of ractopherol and tocoterion that has anti-oxidant effect and acts similar to vitamin E. Shimizu et al. [30], showed that vitamin E enriched diet could be beneficial in the treatment of ulcerative colitis in rats. Ademoglu et al. [25], found that vitamin E and selenium supplementation, significantly reduced both the severity of colonic lesions and the level of MDA and protein carbonyl. Ghalem et al. [31], showed that essential oil from the leaves and the gum of $P$. atlantica has an acceptable antibacterial and antifungal properties.

According to previous studies, it seems that therapeutics role of $P$. atlantica and $H$. perforatum due to their components such as anti-inflammatory properties, and synergic effects similar to vitamin $\mathrm{E}$ that can accelerate healing of oral mucositis. Our findings are in line with this theory. Based on our findings in histopathologic and clinical assessments, we observed that the mixed gel $(10 \%$ P. atlantica $+10 \%$ H. perforatum $)$, had lower microscopic and macroscopic scores compared to the other groups on $15^{\text {th }}$ and $18^{\text {th }}$ day. This reduction in both histopathologic and macroscopic scores indicates the healing process of these therapeutic agents. Oxidative stress from free radical is involved in pathophysiology of many inflammatory diseases, thus, the protective role of $H$. perforatum and $P$. atlantica extracts on the process of lipid peroxidation was determined by measuring the formation of MDA and MPO. We found that MPO and MDA concentration of mixed gel was lower than the others on both days. This study sheds some light on this subject; however, further studies are required to confirm the efficacy of $H$. perforatum and $P$. atlantica in clinical trials.

\section{Conclusion}

This study suggests that daily use of $H$. perforatum and $P$. atlantica gel can relieve the induced oral mucositis in hamsters. A combination of $H$. perforatum and $P$. atlantica with their antioxidant, anti-inflammatory and antimicrobial properties might be a suitable choice for the treatment of oral mucositis.

\section{Acknowledgment}

The authors would like to thank the RCC of Shiraz University of Medical Sciences for their invaluable assistant in editing this article.

\section{Author's Contribution}

FarnazFarrokhi: interpretation of data for the work, drafting the work or revising

Nader Tanideh: conception, design of the work, critical revision of the manuscript

SepidehFekri: analysis, critical revision of the manuscript

Omid Koohi-Hosseinabadi: data gathering, critical revision of the manuscript

AzadehAndishehTadbir: data gathering, critical revision of the manuscript

Maryam Mardani: revising, conception, critical revision of the manuscript

\section{Funding}

The authors would like to thank the Vice-chancellor of research and technology of Shiraz University of Medical Sciences for their financial support. His approval and consent to participate.

The protocol used in the present study was approved by Ethics Research Committee of the Shiraz University of Medical Sciences.

\section{References}

1. Pawar D, Neve R, Kalgane S, Riva A, Bombardelli E, et al. (2013) SAMITAL $®$ improves chemo/radiotherapy-induced oral mucositis in patients with head and neck cancer: results of a randomized, placebocontrolled, single-blind Phase II study. Support Care Cancer 21(3): 
827-834.

2. Putwatana P, Sanmanowong P, Oonprasertpong L, Junda T, Pitiporn S, et al. (2009) Relief of radiation-induced oral mucositis in head and neck cancer. Cancer nurs 32(1): 82-87.

3. Rao S, Dinkar C, Vaishnav LK, Rao P, Rai MP, et al. (2014) The Indian Spice Turmeric Delays and Mitigates Radiation-Induced Oral Mucositis in Patients Undergoing Treatment for Head and Neck Cancer An Investigational Study. Integr Cancer Ther 13(3): 201-210.

4. You WC, Hsieh CC, Huang JT (2009) Effect of extracts from indigowood root (Isatis indigotica Fort.) on immune responses in radiation-induced mucositis. J Altern Complement Med 15(7): 771-778.

5. Babaee N, Moslemi D, Khalilpour M, Vejdani F, Moghadamnia Y, et al. (2013) Antioxidant capacity ofcalendula officinalisflowers extract and prevention of radiation induced oropharyngeal mucositis in patients with head and neck cancers: a randomized controlled clinical study. Daru 21(1): 18.

6. Koohi Hosseinabadi O, Andisheh Tadbir A, Bahadori P, Sepehrimanesh M, Mardani M, et al. (2015) Comparison of the therapeutic effects of the dietary and topical forms of Zizyphus jujuba extract on oral mucositis induced by 5-fluorouracil: a golden hamster model. J Clin Exp Dent 7(2): e304-309.

7. Mardani M, Afra S, Tanideh N, Andisheh Tadbir A, Modarresi F, et al. (2016) Hydroalcoholic extract of Carum carvi L. in oral mucositis: a clinical trial in male golden hamsters. Oral Dis 22(1): 39-45.

8. Tanideh N, Tavakoli P, Saghiri MA, Garcia-Godoy F, Amanat D, et al (2013) Healing acceleration in hamsters of oral mucositis induced by 5-fluorouracil with topical Calendula officinalis. Oral Surg Oral Med Oral Pathol Oral Radiol 115(3): 332-338.

9. Hamidi AR, Naeini AT, Tanideh N, Nazifi S (2015) Effects of Pistacia atlantica (subsp. Mutica) oil extracts on antioxidant activities during experimentally induced cutaneous wound healing in rats. Veterinary Science Development 5(1).

10. Bozorgi M, Memariani Z, Mobli M, Salehi Surmaghi MH, ShamsArdekani MR, et al. (2013) Five Pistacia species (P. vera, P. atlantica, P. terebinthus, $\mathrm{P}$. khinjuk, and P. lentiscus): a review of their traditional uses, phytochemistry, and pharmacology. Scientific World Journal doi: $10.1155 / 2013 / 219815$

11. Dost T, Ozkayran H, Gokalp F, Yenisey C, Birincioglu M (2009) The effect of Hypericum perforatum (St. John's Wort) on experimental colitis in rat. Dig Dis Sci 54(6): 1214-1221.

12. Tanideh N, Namazi F, Tadbir AA, Ebrahimi H, Koohi-Hosseinabadi 0 (2014) Comparative assessment of the therapeutic effects of the topical and systemic forms of Hypericum perforatum extract on induced ora mucositis in golden hamsters. Int J Oral Maxillofac Surg 43(10): 12861292.

13. Lima V, Brito G, Cunha F, Reboucas C, Falcão B, et al. (2005) Effects of the tumour necrosis factor- $\alpha$ inhibitors pentoxifylline and thalidomide in short-term experimental oral mucositis in hamsters. Eur J Oral Sci 113(3): 210-217.

14. Ohkawa H, Ohishi N, Yagi K (1979) Assay for lipid peroxides in animal tissues by thiobarbituric acid reaction. Anal Biochem 95(2): 351-358.

15. Mullane KM, Kraemer R, Smith B (1985) Myeloperoxidase activity as a quantitative assessment of neutrophil infiltration into ischemie myocardium. J Pharmacol Methods J 14(3): 157-167.
16. Samadi S, Khadivzadeh T, Emami A, Moosavi NS, Tafaghodi M, et al. (2010) The effect of Hypericum perforatum on the wound healing and scar of cesarean. J Altern Complement Med 16(1): 113-117.

17.Öztürk N, Korkmaz S, Öztürk Y (2007) Wound-healing activity of St. John's Wort (Hypericum perforatum L.) on chicken embryonic fibroblasts. J Ethnopharmacol 111(1):33-39.

18. Dell'Aica I, Niero R, Piazza F, Cabrelle A, Sartor L, et al. (2007) Hyperforin blocks neutrophil activation of matrix metalloproteinase- 9 , motility and recruitment, and restrains inflammation-triggered angiogenesis and lung fibrosis. J Pharmacol Exp Ther 321(2): 492-500.

19. Conforti F, Statti GA, Tundis R, Menichini F, Houghton P (2002) Antioxidant activity of methanolic extract of Hypericum triquetrifolium Turra aerial part. Fitoterapia 73(6): 479-483.

20. Couladis M, Baziou P, Verykokidou E, Loukis A (2002) Antioxidant activity of polyphenols from Hypericum triquetrifolium Turra. Phytother Res 16(8): 769-770.

21. Božin B, Kladar N, Grujić N, Anačkov G, Samojlik I, et al. (2013) Impact of origin and biological source on chemical composition, anticholinesterase and antioxidant properties of some St. John's Wort species (Hypericum spp., Hypericaceae) from the central Balkans. Molecules 18(10): 11733-11750.

22. Paterniti I, Briguglio E, Mazzon E, Galuppo M, Oteri G, et al. (2010) Effects of Hypericum Perforatum, in a rodent model of periodontitis. BMC Complement Altern Med 10(1): 73.

23. Kashaninejad M, Mortazavi A, Safekordi A, Tabil L (2006) Some physical properties of Pistachio (Pistacia vera L.) nut and its kernel. Journal of Food Engineering 72(1): 30-38.

24. Tanideh N, Masoumi S, Hosseinzadeh M, Safarpour AR, Erjaee H, et al. (2014) Healing effect of pistacia atlantica fruit oil extract in acetic Acidinduced colitis in rats. Iran J Med Sci 39(6): 522.

25. Benhassaini H, Bendahmane M, Benchalgo N (2007) The chemical composition of fruits of Pistacia atlantica desf. subsp. atlantica from Algeria. Chemistry of Natural Compounds 43(2): 121-124.

26. Farhoosh R, Tavassoli-Kafrani MH, Sharif A (2011) Antioxidant activity of the fractions separated from the unsaponifiable matter of bene hull oil. Food Chemistry 126(2): 583-589.

27. Delazar A, Reid R, Sarker S (2004) GC-MS analysis of the essential oil from the oleoresin of Pistacia atlantica var. mutica. Chemistry of Natural Compounds 40(1): 24-27.

28. Ademoglu E, Erbil Y, Tam B, Barbaros U, Ilhan E, et al. (2004) Do vitamin $\mathrm{E}$ and selenium have beneficial effects on trinitrobenzenesulfonic acidinduced experimental colitis. Dig Dis Sci 49(1): 102-108.

29. Farhoosh R, Kafrani MHT (2010) Frying performance of the hull oil unsaponifiable matter of Pistacia atlantica subsp. mutica. European journal of lipid science and technology 112(3): 343-348.

30. Shimizu T, Igarashi J, Ohtuka Y, Oguchi S, Kaneko K, et al. (2001) Effects of n-3 Polyunsaturated Fatty Acids and Vitamin E on Colonic Mucosal Leukotriene Generation, Lipid Peroxidation, and Microcirculation in Rats with Experimental Colitis. Digestion 63(1): 49-54.

31. Ghalem B, Mohamed B (2009) Essential oil from gum of Pistacia atlantica Desf: Screening of antimicrobial activity. African Journal of Pharmacy and Pharmacology 3(1): 13-15. 


\section{Your next submission with Juniper Publishers} will reach you the below assets

- Quality Editorial service

- Swift Peer Review

- Reprints availability

- E-prints Service

- Manuscript Podcast for convenient understanding

- Global attainment for your research

- Manuscript accessibility in different formats

( Pdf, E-pub, Full Text, Audio)

- Unceasing customer service

Track the below URL for one-step submission https://juniperpublishers.com/online-submission.php 